\title{
The Credibility Problem in Unemployment Insurance Policy
}

\author{
Robert A.J. Dur \\ Tinbergen Institute, Erasmus University Rotterdam
}

This draft: January 1999

\begin{abstract}
If distortions in the labour market lead to inefficiently high unemployment, and policy makers cannot enter into a binding policy commitment before nominal wages are set, excessive inflation may result due to a credibility problem. This is the famous Kydland\&Prescott-Barro\&Gordon inflationary bias result. This paper shows that a similar credibility problem may exist in public unemployment insurance policy. I study a model in which trade unions, which set wages, interact with a policy maker, who decides on the level of unemployment benefits and taxes. The policy maker is assumed to have the same preferences as the median voter, whose demand for unemployment benefits is driven by both insurance motives and ideological motives. If the policy maker cannot commit to future policies, and wages are relatively rigid, taxes and benefits are excessively high in equilibrium. Moreover, employment and hence output are inefficiently low in the discretionary equilibrium. Akin to the case of monetary policy, I show that appointing a policy maker who is more conservative than the median voter may solve the credibility problem.
\end{abstract}

Keywords: unemployment insurance policy, credibility problem, trade unions.

JEL codes: D78, J51.

\section{Correspondence address:}

Robert A.J. Dur

Tinbergen Institute

Erasmus University Rotterdam

P.O. Box 1738

3000 DR Rotterdam

The Netherlands

e-mail: dur@few.eur.nl

phone \#: +31-10-408 8924

fax \#: +31-10-408 9031

*I am grateful to Otto Swank for many useful suggestions.

\section{Introduction}


While economists have for a long time been concerned primarily with the question which policies the government should pursue, the now rapidly expanding literature on political economics has dealt with the question why policy makers sometimes fail to implement socially optimal policies. Two seminal papers in this field are Kydland and Prescott (1977) and Barro and Gordon (1983). These studies showed that excessively high inflation may be due to a credibility problem in monetary policy. The basic argument is that a policy of low inflation, although socially optimal, is not credible because policy makers have an incentive to create inflation surprises after nominal wages are set in order to boost employment. As private agents fully anticipate the policy maker's behaviour in equilibrium, excessively high inflation results while employment remains at its natural level.

In this paper I argue that a similar credibility problem may exist in another important area of economic policy making: public unemployment insurance policy. I show that due to a credibility problem, inefficiently high unemployment benefits and taxes may emerge. Moreover, employment and hence output are inefficiently low in equilibrium.

I study a model in which trade unions, which set wages, interact with a policy maker, who decides on the level of unemployment benefits and taxes in accordance with the preferences of the median voter. Trade unions, which operate at the firm-level, maximize the expected utility of workers and rationally regard aggregate variables (in particular, the government budget) as unaffected by their decisions. The implied fiscal externality in wagesetting causes wages and hence unemployment to be too high in equilibrium. This distortion in the labour market affects the policy maker's optimal choice of unemployment insurance policy: in order to induce the trade unions to set lower wages, the policy maker should moderate the generosity of unemployment benefits. This optimal policy, however, suffers from lack of credibility. Once the trade unions have entered into a wage contract, the policy 
maker no longer has an incentive to keep unemployment benefits and taxes low. In equilibrium, the trade unions anticipate this and set wages accordingly. The resulting levels of taxes, benefits, and unemployment are excessively high.

The basic objective of the paper is to provide an explanation for the persistence of inefficiently generous unemployment benefits and inefficiently high taxes. High unemployment benefits and taxes are often held responsible for poor labour market performance, especially in continental Europe. Numerous empirical studies have provided evidence for adverse effects of unemployment benefits on labour force participation and employment (see e.g. the recent survey by Nickell and Layard, forthcoming). Contemporaneously, policy advisors have repeatedly argued that to attain lower unemployment, policy makers should cut unemployment benefits and taxes. Nevertheless, policy makers in Europe have generally failed to implement major reforms in the public unemployment insurance system. I argue that this failure may be the result of a credibility problem: although cuts in unemployment benefits and taxes are in the interest of a majority of voters, they may not be implemented because private agents rationally do not believe that these policy reforms are lasting.

Since the credibility problem arises from wages being rigid in the medium-run while policy is chosen under discretion, institutional reform to overcome the credibility problem should aim at either more flexible wages or more rigid policy formation such that policy makers can commit themselves to the optimal policy. Clearly, both options come at a cost. While recent work has pointed to the benefits of wage rigidity in preventing the hold-up problem associated with firm-specific investment (see Malcomson, 1997), restricting policy flexibility by reforming political institutions delays desirable policy adjustments to structural changes. An alternative way to gain credibility, first suggested by Rogoff (1985) for the case 
of monetary policy, is to delegate policy to an independent policy maker with distorted preferences. Akin to the case of monetary policy, I show that delegating public unemployment insurance policy to an independent policy maker who is more conservative than the median voter may solve the credibility problem.

The paper is related to several strands in the literature. First, the paper is related to the recent literature on the political economy of labour market policy. Wright (1986), Saint-Paul (1996), and Hassler and Rodríguez Mora (1997) study voters' preferences over public unemployment insurance policy. Because unemployment and wages are exogenous in these studies, the credibility problem is non-existent. ${ }^{1}$ Second, the paper is related to the literature on the interaction between trade unions and the government, in particular to Summers, Gruber, and Vergara (1993) and Burda (1997). Summers et al. (1993) study the provision of public goods by a social planner in an economy where trade unions and employers bargain over wages and employment. They implicitly assume that the government can commit to its policy. Burda (1997) studies the interaction between a centralized trade union and a benevolent government in the determination of wages and unemployment benefits. His primary objective is to explore the potential for 'corporatism', i.e. cooperation between the government and a centralized trade union. As in Summers et al. (1993), credibility of government policy is assumed. Third, the paper is related to the huge literature on the credibility problem in macroeconomic policy. Most studies in this field focus on monetary policy, but the insight has also been exploited in wealth taxation and international trade policy. Persson and Tabellini (forthcoming) provide a useful survey of this literature. Closest

\footnotetext{
${ }^{1}$ In one version of Saint-Paul's model, wages and employment are chosen by the median voter, simultaneously with the level of unemployment benefits and taxes, thus precluding the possibility of a credibility problem.
} 
to the present paper is Dixit and Londregan (1995). They show that, in the absence of a binding policy commitment, redistributive policy induces people with desirable political characteristics to make inefficient decisions as they rationally expect to be given offsetting transfers.

The paper is organized as follows. In the next section, I present a brief description of the model. In section 3, the first-best levels of the wage, the tax rate, and the unemployment benefit are derived. Decentralised union wage-setting is introduced in section 4 and the consequences of this distortion for the optimal unemployment insurance policy are examined. Section 5 shows that the optimal policy suffers from a credibility problem and characterises the discretionary equilibrium. In section 6 , I show that delegation of unemployment insurance policy to an independent policy maker who is more conservative than the median voter may solve the credibility problem. Section 7 concludes.

\section{The Model}

In order to focus on the interaction between trade unions and the government, I deliberately keep the model as simple as possible. I consider an economy consisting of a large number of firms operating on imperfectly competitive product markets. Firms employ (homogenous) workers up to the point where the value of the marginal product equals the wage. Unemployment in this economy exists for two reasons. Firstly, "natural turbulence" in the economy creates some unavoidable frictional unemployment. ${ }^{2}$ I capture this by assuming that an exogenous proportion $q$ of all firms are hit by a temporary adverse shock which induces them to lay-off all workers irrespective of the level of the wage. Apart from these shocks,

\footnotetext{
${ }^{2}$ As will become clear below, frictional unemployment is needed to ensure an interior solution.
} 
which are randomly assigned to firms by nature, firms are identical. Secondly, wages may be driven above the market-clearing level by trade unions. I assume that all workers in each firm are organised into a trade union. The trade union unilaterally sets the wage before nature reveals whether the firm is hit by a shock. ${ }^{3}$ Each trade union maximizes the expected utility of its members, subject to the firm's labour demand (cf. e.g. Booth, 1995). The trade union's objective function is:

(1)

$$
U=(1-q)\{n(w) u[(1-\tau) w]+[1-n(w)] u(b)\}+q u(b)
$$

where $n(w)$ is the firm's demand for workers (if not hit by a shock) relative to the total number of union workers, $w$ is the before-tax wage, $\tau$ is the tax rate, $b$ is the level of the unemployment benefit, and the function $u(\cdot)$ is strictly concave. Since trade unions are organised at the firm level, and there exist many firms, the effect of each trade union's decision on aggregate variables is negligible. Hence, each trade union rationally takes the levels of $\tau$ and $b$ as given.

The tax rate and the level of the unemployment benefit are chosen by a policy maker who is appointed before wages are set. Initially, I assume that the preferences of the policy maker coincide with the (ex ante) preferences of the median voter and that the demand for public unemployment insurance policy is driven by insurance motives only. ${ }^{4}$ In section 6 I

\footnotetext{
${ }^{3}$ None of the results below change if we assume that wages are the result of a bargain between the trade union and the firm.

${ }^{4}$ Throughout I assume that private insurance against income loss due to unemployment is impossible. A compelling reason for this is that individual risks are interdependent (for example, if $q$ varies over time). Moreover, if workers face different risks, adverse selection
} 
will add an ideological component to the preferences of voters in order to show that appointing a policy maker who is more conservative than the median voter may be welfare improving. It seems reasonable to assume that the median voter is a worker, even for countries with very low employment (cf. Wright, 1986, and Saint-Paul, 1996). With homogeneous workers, the policy maker's objective function is thus given by (1). The policy maker's budget constraint is:

(2)

$$
\tau w(1-q) n(w)=\{[1-q][1-n(w)]+q+f\} b
$$

where $f$ is the number of beneficiaries per worker who for exogenous reasons no longer belong to the work force (i.e. do not search for a job). While it will generally be in the interest of workers to exclude these people from relying on the public unemployment insurance scheme, I assume that lack of information about individual job search behaviour precludes this, at least to some extent. ${ }^{5}$

\section{The First-best as a Benchmark}

A necessary condition for the existence of a credibility problem in public unemployment insurance policy is that unemployment is inefficiently high in equilibrium. The distortion

may break down private insurance markets.

${ }^{5}$ As will become clear below, this distortion is introduced in order to exclude full insurance ( $b=[1-\tau] w)$ as the optimum. Alternatively or additionally, I could have assumed that the unemployment benefit scheme distorts job search behaviour of the unemployed, or I could have introduced heterogeneity among workers. These amendments clearly result in a more complicated model, while the main results need not be affected. 
responsible for inefficiently high unemployment in the present model is a fiscal externality in wage-setting. Wages are determined by trade unions, operating at the firm-level, which (rationally) do not take into account the effect of their decisions on the government budget. Before turning to the determination of public unemployment insurance policy under unionised wage-setting, it is useful to characterise the equilibrium that would prevail if there was no fiscal externality in wage-setting. This equilibrium can be interpreted as a first-best optimum, ${ }^{6}$ and would arise if the policy maker had complete discretion over both the level of wages and unemployment insurance policy. The first-best optimum is defined by the solution to the following optimisation problem:

(3) $\max _{w, \tau}(1-q)\{n(w) u[(1-\tau) w]+[1-n(w)] u(b)\}+q u(b)$

$$
\text { subject to } b=\frac{\tau w(1-q) n(w)}{(1-q)[1-n(w)]+q+f}
$$

After some rewriting, the first-order conditions are:

(4)

$$
\begin{gathered}
V_{w}=\left[\frac{(1-q) n(w)}{w}\right]\left\{(1-\tau) w u^{\prime}[(1-\tau) w]-\eta\{u[(1-\tau) w]-u(b)\}+\right. \\
\left.+\tau w \frac{(1-q)[1-n(w)]+q}{\{(1-q)[1-n(w)]+q+f\}^{2}}(\{(1-q)[1-n(w)]+q+f\}(1-\eta)-(1-q) n(w) \eta) u^{\prime}(b)\right\}=0
\end{gathered}
$$

(5)

$$
V_{\tau}=w(1-q) n(w)\left\{-u^{\prime}[(1-\tau) w]+\frac{(1-q)[1-n(w)]+q}{(1-q)[1-n(w)]+q+f} u^{\prime}(b)\right\}=0
$$

${ }^{6}$ First-best as defined here does not necessarily imply Pareto-efficiency, since I focus on the welfare of workers (the decisive voters) only. Note also that I maintain $f>0$ in this section. 
where $V$ is the objective function of the policy maker, subscripts denote partial derivatives, and $\eta$ is the (absolute value of the) elasticity of labour demand with respect to the wage. The second-order conditions are satisfied under two mild assumptions (see the Appendix). Firstorder condition (4) characterises the first-best level of the wage. The first two terms in (4) represent the marginal benefit (higher income if employed) and the marginal cost (worsening of job prospects) of a wage increase for a given level of the tax rate and benefit level. The third term in (4) represents the effect of a wage increase on the government budget. Wages affect the government budget in two ways. First, the level of the wage affects tax receipts. Clearly, if $\eta>1$, tax receipts decrease in the wage. Second, the number of beneficiaries increases as the wage goes up. In sum, a wage increase implies a tightening of the government budget (and hence the third term in (4) is negative), under a very mild condition on the labour demand elasticity. ${ }^{7}$ It is easy to show that first-order conditions (4) and (5) together imply that full employment $[n(w)=1]$ is first-best optimal if $\eta$ is at least greater than one. The intuition is that for $\eta>1$ the total pie to be distributed over the employed and unemployed workers decreases in the level of the wage. ${ }^{8}$ Empirical studies suggest a value of $\eta$ between 0.3 and 0.8 , but measurement problems possibly bias the estimates downwards (Hamermesh, 1993). For ease of exposition, I will assume that the first-best level of the wage implies full employment, but none of the results below change if above market-clearing wages are optimal for the policy maker. First-order condition (5) characterises the first-best level of the

${ }^{7}$ The condition is $\eta>\frac{(1-q)[1-n(w)]+q+f}{1+f}$. Thus, the labour demand elasticity must be greater than the proportion of nonemployed. A closely resembling condition is derived in Mulder (1993).

${ }^{8}$ Note also that the value of $\eta$ necessary for full employment to be first-best optimal decreases in $f$. 
unemployment benefit relative to the after-tax wage (the "net replacement rate"). Clearly, if $f$ is zero, full insurance is optimal. This is due to our assumptions that workers are risk averse, face similar job prospects, and that the unemployment insurance scheme does not distort search behaviour. For $f>0$, which is assumed, the unemployment insurance scheme is not actuarially fair, and therefore the optimal level of the unemployment benefit is lower than the after-tax wage. Note finally that even if first-order condition (4) implies full employment $[n(w)=1]$, the first-best levels of the tax rate and benefit level are positive because there is always a probability to end up unemployed due to natural turbulence $(q>0)$.

\section{The Second-best: Commitment to an Optimal Plan}

The analysis in the previous section showed that economy-wide full employment is likely to be first-best optimal for workers. At the firm-level, however, workers may have an incentive to organize into a trade union and raise the wage above the market-clearing level. The reason for this in the present model is a common pool problem: while workers in each firm fully reap the benefits of higher wages, they internalise only part of the costs because the public unemployment insurance scheme is paid for by all workers in the economy. In other words, there is a fiscal externality in wage-setting. ${ }^{9}$ Formally, each trade union maximizes the expected utility of its members, given by equation (1), regarding the (expected) levels of $\tau$ and $b$ as unaffected by its decision. The resulting first-order condition is:

(6) $U_{w}=\left[\frac{(1-q) n(w)}{w}\right]\left((1-\tau) w u^{\prime}[(1-\tau) w]-\eta\{u[(1-\tau) w]-u(b)\}\right)=0$

${ }^{9}$ A number of other externalities in decentralised wage-setting have been identified in the literature (see Calmfors, 1993, for a useful survey). These externalities, as well as other reasons why wages and unemployment may be inefficiently high, are for simplicity neglected. 
The second-order condition is satisfied under a mild condition (see the Appendix). Sufficient for an interior optimum is that $\eta$ is not too large, which is assumed. Comparing first-order conditions (4) and (6), it is easy to see that wages, and hence unemployment, are higher under decentralised wage-setting because trade unions rationally do not take into account that the government budget tightens if wages go up.

Clearly, the workers (and hence the policy maker) are less well-off due to the distortion in the labour market. Although it is fully rational at the micro-level to drive up wages, the macro-outcome is suboptimal as the tax base shrinks and the number of people living on an unemployment benefit increases, implying either inefficiently high taxes and/or inefficiently low unemployment benefits. The policy maker can try to bring wages and employment closer to their first-best levels in two ways. First, she can try to eliminate the distortion in the labour market. For example, she may reduce the power of trade unions through legislative reform. I assume that the policy maker can not completely prevent wages and unemployment from being too high. This basically reflects a lack of non-distorting policy instruments. ${ }^{10}$ Second, the policy maker can try to induce trade unions to set lower wages by announcing a frugal public unemployment insurance policy. Applying the implicit function theorem to first-order condition (6), the effect of unemployment insurance generosity on union wages is given by:

(7) $\frac{\partial w}{\partial \tau}=\frac{U_{w \tau}}{-U_{w w}}$

${ }^{10}$ Unionised wage-setting is not a necessary condition for the existence of the credibility problem in unemployment insurance policy. The main results of this paper carry over to the case wherein unemployment is due to "efficiency wages" set by the firm, as long as the efficient wage increases in benefit generosity and the tax rate (as in e.g. Phelps, 1994). 
where $\frac{\partial w}{\partial \tau}$ captures both the effect of a higher unemployment benefit and the effect of the increase in the tax rate needed to keep the government budget balanced. $U_{w w}$ is the secondorder condition, which is satisfied under a mild condition on the utility function (see the Appendix). ${ }^{11}$ To find $U_{w \tau}$, we substitute the government budget constraint for $b$ into (6), and differentiate (6) with respect to $\tau$, which results in:

(8)

$$
\begin{aligned}
& U_{w \tau}=\left[\frac{(1-q) n(w)}{w}\right]\left\{-(1-\tau) w^{2} u^{\prime \prime}[(1-\tau) w]-(1-\eta) w u^{\prime}[(1-\tau) w]+\right. \\
& \left.+\eta \frac{(1-q) n(w) w}{(1-q)[1-n(w)]+q+f} u^{\prime}(b)\right\}
\end{aligned}
$$

If the second-order condition is satisfied, $U_{w \tau}$ is positive. Hence, an increase in the generosity of unemployment benefits, accompanied by a rise in the tax rate such that the government budget remains balanced, induces the trade unions to set higher wages. The intuition is straightforward. More generous unemployment benefits and higher taxes narrow the gap between employed workers' income and unemployed worker's income and thus reduces the utility loss of becoming unemployed. Hence, the cost of setting above market-clearing wages is lower at the margin. Therefore, unions will set higher wages in response to a rise in taxes and benefits.

Potentially, the policy maker can bring employment and wages back to their first-best levels by making the trade unions believe that public unemployment insurance policy will be very moderate. Indeed, if the policy maker announces that the unemployed will be paid no benefit at all, and the trade unions believe this, wages are likely to be set at their first-best

\footnotetext{
${ }^{11}$ The condition is that the coefficient of relative risk aversion, defined as $\frac{-c u^{\prime \prime}(c)}{u^{\prime}(c)}$, is greater than 1- $\eta$, which seems reasonable (cf. Blanchard and Fischer, 1989).
} 
level. Clearly, such a policy announcement will not be believed by the trade unions, and hence it will not affect their behaviour. In order to be effective, a policy announcement must be credible. Credibility is guaranteed if the policy maker can precommit to a policy before wages are set. Assuming that a commitment technology is available, the optimal (second-best) unemployment insurance policy is characterised by the following first-order condition:

$$
\text { (9) } \quad V_{\tau}+\frac{\partial w}{\partial \tau} V_{w}=0
$$

where $V_{\tau}$ and $V_{w}$ are given by (4) and (5), and $\frac{\partial w}{\partial \tau}$ is given by (7). Since the wage set by the trade unions is too high from the policy maker's point of view, $V_{w}$ is negative. Hence, since $\frac{\partial w}{\partial \tau}>0$, the optimal unemployment insurance policy is no longer characterised by $V_{\tau}=0$. Clearly, the distortion in the labour market makes that the policy maker is willing to compromise on her most-preferred unemployment insurance policy in order to bring wages, and hence employment, closer to the first-best level. Since $V_{w}$ is negative and $\frac{\partial w}{\partial \tau}>0$, it follows from (9) that $V_{\tau}$ is positive in the second-best optimum. Thus, the second-best optimal policy implies that the policy maker moderates the generosity of unemployment benefits in order to induce the trade unions to set lower wages. Wages and unemployment will nevertheless be higher than in the first-best optimum, as (9) implies $V_{w}<0$.

\section{The Third Best: Discretion}

In the previous section we derived the optimal unemployment insurance policy under the assumption that the policy maker can commit to the level of the unemployment benefit and the tax rate before unions set wages. In practice, however, policy makers may not be able to credibly commit to a policy. If policy decisions can be revised from time to time, while wages 
are relatively rigid, the second-best optimal policy derived above is not incentive compatible.

Consider again first-order condition (9). The policy maker compromises on her mostpreferred unemployment insurance policy in order to induce the trade unions to set lower wages. Assume that the policy maker can revise her decision after the trade unions have set wages, which are fixed in the medium-run. One reason for rigid wages may be that it is in the trade unions' interest to prevent the hold-up problem associated with firm-specific investment (see Malcomson, 1997). The policy maker faces a different trade-off after wages are set. Since $w$ is fixed, at least in the medium-run, $\frac{\partial w}{\partial \tau}$ is equal to zero. Hence, after wages are set, the policy maker will have an incentive to increase the level of the unemployment benefit and the tax rate since the trade unions need no longer be induced to set lower wages.

Clearly, in equilibrium the trade unions will foresee the policy maker's behaviour and set wages accordingly. Formally, they will maximize objective function (1) with respect to $w$, rationally expecting $\tau$ and $b$ to be given by $V_{\tau}=0$ instead of first-order condition (9). After wages are set, the policy maker has no incentive to 'surprise' the trade unions: she will set the tax rate and benefit level such that $V_{\tau}=0$. Thus, in the discretionary (third-best) equilibrium, we have $U_{w}=0$ and $V_{\tau}=0$. Hence, in comparison with the second-best optimum, wages, unemployment, taxes, and the level of the unemployment benefit are inefficiently high. The inability to precommit makes that the policy maker cannot credibly compromise on the generosity of unemployment insurance in order to induce the trade unions to set lower wages.

\section{The Case for a Conservative Policy Maker}

Since the credibility problem arises from wages being rigid in the medium-run while policy is chosen under discretion, ways to overcome the problem are to increase wage flexibility and/or make it harder for policy makers to change policy. Both ways, the second-best optimum may 
become feasible, because the policy maker can credibly commit to a policy. An alternative way to gain credibility, first suggested by Rogoff (1985) for the case of monetary policy, is to delegate policy to an independent policy maker with distorted preferences. By delegating policy, the second-best policy may become incentive compatible in a third-best environment. In this section, I show that, akin to the case of monetary policy, delegating public unemployment insurance policy to an independent policy maker who is more conservative than the median voter may solve the credibility problem.

In order to show this, we need to add an ideological component to the objective function of voters. A simple way to introduce ideology is to add the term $\alpha_{i} u(b)$ to the voter's objective function (1). $\alpha_{i}$ measures in how far voter $i$ is biased towards high unemployment benefits relative to her insurance-motivated most-preferred level. I assume that voters differ in $\alpha_{i}$ and, for ease of comparison, that the median voter has $\alpha_{m}=0$ (thus, the median voter's objective function is still given by (1)). Voters with negative $\alpha_{i}$ intrinsically dislike taxation and benefits, and are denoted as 'conservatives'.

Assume that the median voter can delegate policy to a policy maker with a different ideological position, denoted by $\alpha_{p}$. What is the optimal $\alpha_{p}$ ? Differentiating the objective function (1) with respect to $\alpha_{p}$, treating $\tau, b$, and $w$ as endogenous, results in:

$$
\frac{\partial \tau}{\partial \alpha_{p}}\left(V_{\tau}+\frac{\partial w}{\partial \tau} V_{w}\right)=0
$$

where $V_{\tau}$ and $V_{w}$ are given by (4) and (5), and $\frac{\partial w}{\partial \tau}$ is given by (7). In the third-best equilibrium, the term in brackets is negative (recall, $V_{\tau}=0$ and $V_{w}<0$ ). Hence, delegating policy to a policy maker with identical preferences $\left(\alpha_{p}=\alpha_{m}=0\right)$ is not optimal. For the term in brackets to be zero, the tax rate and the wage must both be lower than in the discretionary 
equilibrium such that $V_{\tau}$ becomes positive and $V_{w}$ becomes closer to zero. This can only be the case for $\alpha_{p}<0$, since $\frac{\partial \tau}{\partial \alpha_{p}}>0$ and $\frac{\partial w}{\partial \tau}>0$. Hence, first-order condition (10) implies that it is in the interest of the median voter to delegate public unemployment insurance policy to a policy maker who is more conservative than herself. The intuition is clear. In contrast to a policy maker whose preferences coincide with the preferences of the median voter, a conservative policy maker can credibly commit to low taxes and benefits. Comparing (10) and (9), it follows that the median voter will appoint a policy maker who can credibly commit to the second-best levels of the unemployment benefit and the tax rate. An ultraconservative policy maker (one that would never provide benefits to the unemployed and set the tax rate to zero) is not optimal, even if it would result in full employment. The reason is, of course, that there is always some probability to end up unemployed due to natural turbulence.

\section{Conclusions}

The basic aim of this paper is to provide an explanation for the persistence of inefficiently generous public unemployment insurance and, as a consequence, inefficiently high unemployment. Using a model wherein trade unions set wages and a policy maker chooses unemployment insurance policy in accordance with the preferences of the median voter, I have shown that a cut in unemployment benefits and taxes, although in the interest of a majority of voters, may not be implemented due to a credibility problem. Further, I have shown that appointing an independent policy maker who is more conservative than the median voter may solve the credibility problem.

While the model developed in this paper is deliberately kept simple, I believe that the main results carry over to more general settings. Three features of my model are of crucial importance for the results. First, distortions in the labour market keep employment inefficiently low. Second, wages are rigid in the medium run, while policy is chosen under 
discretion. Third, wages rise in response to more generous unemployment benefits.

An interesting extension would be to study the issue in a dynamic setting. Repeated interaction between the policy maker and the trade unions may restore credibility through reputational forces, as the literature on the credibility problem in monetary policy indicates. Moreover, in such a framework, one could include various dynamic aspects of labour markets, for instance hysteresis. Quite likely, however, multiple equilibria result which poses the problem of how the players coordinate on a particular equilibrium.

\section{References}

Barro, R. and D. Gordon (1983), Rules, Discretion, and Reputation in a Model of Monetary Policy, Journal of Monetary Economics, 12, p. 101-122.

Blanchard, O.J., and S. Fischer (1989), Lectures on Macroeconomics, Cambridge, MA: MIT Press.

Booth, A.L. (1995), The Economics of the Trade Union, Cambridge: Cambridge University Press.

Burda, M.C. (1997), Corporatism, Labor Unions, and the Safety Net, European Economic Review, 41, p. 635-646.

Calmfors, L. (1993), Centralisation of Wage Bargaining and Macroeconomic Performance: A Survey, OECD Economics Department Working Paper No. 131, Paris.

Dixit, A., and J. Londregan (1995), Redistributive Politics and Economic Efficiency, American Political Science Review, 89, p. 856-866.

Hamermesh, D.S. (1993), Labor Demand, Princeton: Princeton University Press. 
Hassler, J., and J. Rodríguez Mora (1997), Employment Turnover and Unemployment Insurance, CEPR Discussion Paper No. 1609.

Kydland, F. and E. Prescott (1977), Rules Rather Than Discretion: The Inconsistency of Optimal Plans, Journal of Political Economy, 85, p. 473-490.

Malcomson, J.M. (1997), Contracts, Hold-Up, and Labor Markets, Journal of Economic Literature, 35, p. 1916-1957.

Mulder, C.B. (1993), Wage-moderating Effects of Corporatism: Decentralised Versus Centralised Wage Setting in a Union, Firm, Government Context, The Manchester School, 61, p. 287-301.

Nickell, S. and R. Layard (forthcoming), Labour Market Institutions and Economic Performance, in O. Ashenfelter and D. Card (eds.), Handbook of Labor Economics, Amsterdam: North-Holland.

Persson, T. and G. Tabellini (forthcoming), Political Economics and Macroeconomic Policy, in J. Taylor and M. Woodford (eds.), Handbook of Macroeconomics, Amsterdam: NorthHolland.

Phelps, E.S. (1994), Structural Slumps: the Modern Equilibrium Theory of Unemployment, Interest, and Assets, Cambridge, MA: Harvard University Press.

Rogoff, K. (1985), The Optimal Degree of Commitment to an Intermediate Monetary Target, Quarterly Journal of Economics, 100, p. 1169-1190.

Saint-Paul, G. (1996), Exploring the Political Economy of Labour Market Institutions, Economic Policy, 23, p. 265-315.

Summers, L., J. Gruber, and R. Vergara (1993), Taxation and the Structure of Labor Markets: 
The Case of Corporatism, Quarterly Journal of Economics, 108, p. 385-411.

Wright, R. (1986), The Redistributive Roles of Unemployment Insurance and the Dynamics of Voting, Journal of Public Economics, 31, p. 377-399. 


\section{Appendix}

Assuming a constant $\eta$, the second-order conditions associated with optimisation problem (3) are:

(A1) $V_{\tau \tau}=w^{2}(1-q) n(w) u^{\prime \prime}[(1-\tau) w]+\frac{[(1-q) n(w) w]^{2}}{1-n(w)}\left\{\frac{(1-q)[1-n(w)]+q}{(1-q)[1-n(w)]+q+f}\right\} u^{\prime \prime}(b)<0$

which is always satisfied, and

(A2) $V_{w w}=\frac{(1-q) n(w)}{w}\left\{(1-\eta)(1-\tau) u^{\prime}[(1-\tau) w]+\eta \frac{\partial b}{\partial w} u^{\prime}(b)+(1-\tau)^{2} w u^{\prime \prime}[(1-\tau) w]+\right.$ $\left.+\left(\eta+\frac{(1-q)[1-n(w)]+q}{(1-q) n(w)}(1+\eta)\right) \frac{\partial b}{\partial w} u^{\prime}(b)+w \frac{(1-q)[1-n(w)]+q}{(1-q) n(w)}\left[\frac{\partial^{2} b}{\partial w^{2}} u^{\prime}(b)+\left(\frac{\partial b}{\partial w}\right)^{2} u^{\prime \prime}(b)\right]\right\}<0$ where $\frac{\partial b}{\partial w}$ is the partial derivative of the policy maker's budget constraint (2) with respect to $w:$

(A3) $\frac{\partial b}{\partial w}=\tau \frac{(1-q) n(w)}{(1-q)[1-n(w)]+q+f}\left[1-\eta \frac{1+f}{(1-q)[1-n(w)]+q+f}\right]$

which is negative if the elasticity of labour demand with respect to the wage is greater than the proportion of nonemployed, and

(A4) $\frac{\partial^{2} b}{\partial w^{2}}=-\frac{\eta \tau}{w} \frac{(1-q) n(w)(1+f)}{\{(1-q)[1-n(w)]+q+f\}^{2}}\left[1-\eta \frac{1+f+(1-q) n(w)}{(1-q)[1-n(w)]+q+f}\right]$

Straightforward but tedious algebra shows that for the second-order condition to be satisfied it is sufficient to assume that individuals are sufficiently risk averse and that the elasticity of 
labour demand is not too small. More specifically, if the coefficient of relative risk aversion, defined as $\frac{-c u^{\prime \prime}(c)}{u^{\prime}(c)}$, is equal to one, it must hold that:

(A5) $\quad \eta>\frac{2+\gamma}{2+\gamma+\varphi(2-\gamma \varphi)}$

where $\gamma=\frac{(1-q)[1-n(w)]+q}{(1-q) n(w)}$ and $\varphi=\frac{(1-q) n(w)}{(1-q)[1-n(w)]+q+f}$. Hence, if the coefficient of relative risk aversion is one, $\eta>1$ is sufficient. If the coefficient of relative risk aversion is larger than one, the condition on $\eta$ becomes even less restrictive.

The second-order condition associated with the trade union's optimization problem is:

(A6) $U_{w w}=\frac{(1-q) n(w)}{w}\left\{(1-\eta)(1-\tau) u^{\prime}[(1-\tau) w]+(1-\tau)^{2} w u^{\prime \prime}[(1-\tau) w]\right\}<0$

which is satisfied if the coefficient of relative risk aversion is greater than $1-\eta$.

The second-order conditions associated with the policy maker's optimisation problem in sections 4 and 5, and the voter's optimisation problem in section 6 , depend on the sign of $\boldsymbol{u}^{\prime \prime \prime}(\cdot)$, and are therefore imposed. 